\title{
A ESTRATÉGIA ESPACIAL DE INTERNACIONALIZAÇÃO DE EMPRESAS BRASILEIRAS DO SETOR FRIGORÍFICO: OS CASOS DA JBS E DA MINERVA ${ }^{1}$
}

\author{
THE SPATIAL STRATEGY FOR INTERNATIONALIZATION \\ OF BRAZILIAN COMPANIES IN THE MEATPACKING \\ SECTOR: THE CASE OF JBS AND MINERVA
}

\author{
LA ESTRATEGIA ESPACIAL DE INTERNACIONALIZACIÓN DE EMPRESAS \\ BRASILEÑAS DEL SECTOR FRIGORÍFICO: EL CASO DE JBS Y DE MINERVA \\ Onofre Aurélio Neto - Secretaria Municipal de Educação e Esporte - Goiânia - Goiás - Brasil \\ opan.neto@yahoo.com.br
}

\begin{abstract}
Resumo
A internacionalização de empresas brasileiras é um fenômeno recente e que chama atenção pelo acelerado processo de abertura de unidades de produção no exterior. Ao averiguar barreiras comerciais que afetam as exportações brasileiras de carne bovina, constatou-se que as medidas restritivas existentes no comércio internacional de carne impulsionaram a dispersão geográfica de empresas brasileiras para fora do território nacional, com o intuito de aumentarem as suas participações no mercado mundial. A partir do estudo de caso das multinacionais JBS e Minerva, verificou-se que a abertura de filiais em territórios estrangeiros é uma estratégia espacial adotada pelas empresas, uma vez que a localização das unidades de produção visa acessar mercados-alvo internos e externos. Ao dispor de uma ampla plataforma de produção e comercialização, estrategicamente posicionada, as multinacionais brasileiras da carne estabeleceram uma integração direta com os principais mercados globais e alavancaram suas receitas operacionais.

Palavras-chave: Internacionalização. Barreiras comerciais. Estratégia espacial.
\end{abstract}

\begin{abstract}
Internationalization of Brazilian companies is a recent phenomenon that calls attention to the accelerated process of opening production facilities abroad. Upon assessing trade barriers affecting Brazilian beef exports, it was found that restrictive measures in the international meat trade propelled the geographical dispersion of Brazilian companies outside the national territory, with the aim of increasing their share in the global market. The case study of the multinational corporations JBS and Minerva has found that opening branches in foreign territories is a spatial strategy adopted by the companies, since the location of production facilities aims to access domestic and foreign target markets. By having a large, strategically positioned production and marketing platform, Brazilian meat multinationals have established direct integration with major global markets and leveraged their operating revenues.
\end{abstract}

Keywords: Internationalization. Trade barriers. Spatial strategy.

\section{Resumen}

La internacionalización de empresas brasileñas es un fenómeno reciente y que llama la atención por el acelerado proceso de apertura de plantas de producción en el exterior. Al analizar las barreras comerciales que afectan a las exportaciones brasileñas de carne bovina, se constató que las medidas restrictivas existentes en el comercio internacional de carne impulsaron la dispersión geográfica de empresas brasileñas fuera del territorio nacional, con el fin de aumentar sus participaciones en el mercado global. A partir del estudio de caso de las multinacionales JBS y Minerva, se verificó que la apertura de filiales en territorios extranjeros es una 
estrategia espacial adoptada por las empresas, ya que la ubicación de las unidades de producción tiene por objeto acceder a mercados objetivo internos y externos. Al disponer de una amplia plataforma de producción y comercialización, estratégicamente posicionada, las multinacionales cárnicas brasileñas establecieron una integración directa con los principales mercados globales y apalancar sus ingresos operativos.

Palabras clave: Internacionalización. Barreras comerciales. Estrategia espacial.

Introdução

Apesar das tentativas da Organização Mundial de Comércio (OMC) de eliminar barreiras tarifárias e não tarifárias nas relações comerciais, em prol de um mercado mundial sem tantas medidas protecionistas, a existências dessas e as recentes ações de líderes de Estados-nações revelam que o mercado mundial ainda é um espaço econômico fragmentado e disputado. Os governos estabelecem barreiras comerciais para onerar ou mesmo restringir a atuação do capital estrangeiro em seus territórios, alegando a defesa de interesses nacionais, como se observa no discurso do presidente Donald Trump.

Segundo Ordoñez et al. (2007), foi a partir da década de 1930 que o protecionismo e as restrições ao comércio internacional passaram a ser o marco institucional de toda a economia mundial. Desde então, as intervenções dos Estados nacionais nos mercados afetam as exportações de carnes, apesar das tentativas de criação de um "comércio livre" e dos avanços ocorridos no âmbito do General Agreeement on Tariffs and Trade (GATT) e de sua sucessora, a OMC. Para contornar barreiras comerciais impostas pelas políticas protecionistas de outros países, de acordo com Hilferding (1981), desde o início do século XX as nações mais desenvolvidas estimularam a exportação de capital no lugar da exportação de mercadorias, ao deslocar parte da produção para países estrangeiros.

Já na década de 1970, os autores Brandt e Hulbert (1977, p. 179) defendiam que a empresa nacional devia "se deslocar para fora dos limites das fronteiras brasileiras e tornar-se multinacionais de pleno direito". Essa afirmação encontra respaldo no fato de que somente ao se tornarem multinacionais as empresas brasileiras teriam alta competitividade no mercado mundial, visto que os países impõem diferentes barreiras ao comércio exterior a fim de protegerem as suas produções locais.

Contudo, a trajetória inversa do processo de internacionalização, com a abertura de filiais no exterior por empresas de países considerados subdesenvolvidos ou emergentes, ganhou força somente no final do 
século XX e início do século XXI. Dessa maneira, conforme Mathews (2006), as multinacionais de países emergentes passaram a desafiar a lógica estabelecida na economia global até então, a qual privilegiou as corporações dos centros econômicos, e passam a operar em diversos mercados globais.

No caso do setor frigorífico brasileiro, as empresas JBS, Minerva, Marfrig e BRF optaram por avançar no processo de internacionalização com o Investimento Direto Estrangeiro (IDE), adquirindo unidades operacionais fora do Brasil, tais como escritórios comerciais e plantas industriais, o que as caracterizam como multinacionais. Dentre as empresas supracitadas, as duas primeiras foram selecionadas para aprofundar esta pesquisa, o que se deve ao fato de atuarem com foco no processamento de carne bovina.

Para Michalet (2003), uma multinacional é uma empresa que a partir de uma base nacional implantou filiais fora do seu país de origem, expandido seu espaço econômico ao adotar uma estratégia e uma organização em escala mundial. Nesse sentido, a internacionalização pode ser considerada uma estratégia espacial utilizada por empresas para superarem impasses existentes no comércio exterior, ampliarem o quadro de fornecedores e o mercado consumidor; ao mesmo tempo em que favorece a competitividade, pois as filiais operam dentro ou próximas do mercado-alvo.

A estratégia espacial, como discute o geógrafo André Fischer (1979), está relacionada à seleção de locais adequados para a atuação da empresa, nos quais se consideram a produtividade e a competitividade. Para uma melhor compreensão dessa temática, o artigo apresenta como objetivos: analisar a influência de barreiras comerciais que atingem o setor de carne bovina na estratégia espacial de internacionalização de empresas brasileiras; avaliar o papel do Estado/BNDES na alavancagem das multinacionais selecionadas; e averiguar a correlação entre o número de unidades de produção no exterior e a receita operacional da JBS e Minerva.

Para tanto, a partir de pesquisa bibliográfica e documental, averiguou-se barreiras comerciais que existem no mercado mundial de carne bovina. Paralelamente, utilizando-se de dados secundários, elaborou-se um quadro demonstrativo da participação do Brasil na oferta de carne bovina nos principais mercados importadores. Em seguida, adentrou-se no estudo de caso das multinacionais brasileiras JBS e 
Minerva para conhecer suas formas de dispersão geográfica, identificando os países em que dispunham de unidades de produção e os principais mercados atendidos pelas filiais. Esta parte do trabalho baseou-se nos relatórios anuais das empresas e em trabalho de campo.

Além disso, com o intuito de demonstrar o grau de correlação existente entre o número de "unidades de produção (UP) no exterior" e a variação na "receita operacional" das multinacionais, adotou-se o Coeficiente de Correlação Linear de Pearson (Função Correl). Segundo Rogerson (2012), esse coeficiente é uma covariância com valores no intervalo de $-1,0$ a 1,0, sendo que os valores positivos próximos de 1 indicam um forte grau de associação entre as variáveis, as quais estariam diretamente correlacionadas.

Barreiras comerciais no mercado mundial de carne bovina

Conforme Da Mata e Freitas (2006, p. 371), as barreiras comerciais "podem se manifestar em formas relativamente explícitas com tarifas ad valorem ou em formatos menos transparentes, a exemplo de barreiras sanitárias, fitossanitárias ou mesmo regulamentações técnicas e/ou e rotulagem”. Assim, entre as barreiras comerciais podemos distinguir duas categorias mais comuns: as barreiras tarifárias, com tarifas de importações, taxas diversas e sobretaxas; e as barreiras não tarifárias, tais como fixação de cotas que limitam as importações, medidas sanitárias e fitossanitárias etc.

No caso das barreiras tarifárias, o aumento do preço da carne com as taxas aduaneiras ocasiona uma redução no consumo do produto estrangeiro, devido às tarifas que elevam os custos aos consumidores no país importador. Assim, o setor frigorífico localizado naquele país tende a ser favorecido por não sofrer as mesmas taxações. Essa situação é percebida nas exportações de carnes do Brasil para alguns dos principais mercados consumidores no mundo.

Como consta na Tabela 1, apesar dos Estados Unidos serem os maiores importadores mundiais de carne bovina, a participação brasileira nesse mercado mantém-se abaixo de $3 \%$. No ano 2000, os EUA importaram 1,3 milhão de tonelada de carne bovina, o que representou $23,7 \%$ do volume mundial, mas as remessas brasileiras para o país foram de apenas 38.077 toneladas. Sendo o volume enviado dos frigoríficos localizados no 
Brasil ainda menor em 2016, quando a participação brasileira foi de 2,4\%. Isso nos ajuda a compreender o anseio de algumas empresas brasileiras do setor frigorífico por instalarem unidades operacionais dentro do território norte-americano.

As barreiras comerciais também restringem a participação brasileira no mercado japonês. De acordo com Silva et al. (2008), o Japão aplica elevadas tarifas de importação sobre a carne produzida em território estrangeiro, sendo a tarifa ad valorem para a carne bovina in natura em torno de $28 \%$, com mínimo de $12,8 \%$ e máximo de $50 \%$ para cortes de carne resfriada, refrigerada ou congelada. Entre 2000 e 2016, as participações das remessas do Brasil estiveram abaixo de $1 \%$ do volume importado pelo Japão, apresentando queda significativa ao longo do período analisado, de 1.914 toneladas para quatro toneladas (ABIEC, 2016). Em parte, isso se deve às restrições comerciais impostas ao produto brasileiro e a opção do Japão em obter carnes de países da Oceania e Ásia.

Tabela 1 - Principais mercados importadores de carne bovina no mundo e o volume procedente do território brasileiro, por mil toneladas (2000/2016)

\begin{tabular}{l|c|c|c|c|c|c|}
\hline \multirow{2}{*}{$\begin{array}{c}\text { Mercado } \\
\text { importador }\end{array}$} & \multicolumn{3}{|c|}{$\mathbf{2 0 0 0}$} & \multicolumn{3}{c|}{$\mathbf{2 0 1 6}$} \\
\cline { 2 - 7 } & $\begin{array}{c}\text { Importação } \\
\text { total }\end{array}$ & $\begin{array}{c}\text { Remessas } \\
\text { brasileiras }\end{array}$ & $\begin{array}{c}\text { Participação } \\
\text { (\%) }\end{array}$ & $\begin{array}{c}\text { Importação } \\
\text { total }\end{array}$ & $\begin{array}{c}\text { Remessas } \\
\text { brasileiras }\end{array}$ & $\begin{array}{c}\text { Participação } \\
\text { (\%) }\end{array}$ \\
\hline Estados Unidos & 1.375 & 38 & 2,8 & 1.368 & 33,2 & 2,4 \\
China & 16 & 0,631 & 3,8 & 812 & 165,7 & 20,4 \\
Japão & 1.045 & 1,914 & 0,2 & 719 & 0,004 & 0,0 \\
Rússia & 425 & 0 & - & 518 & 138,7 & 26,8 \\
Coreia do Sul & 333 & 0,216 & 0,1 & 513 & 0,175 & 0,0 \\
Hong Kong & 71 & 30,2 & 42,5 & 453 & 330,5 & 73,0 \\
União Europeia & 429 & 179,9 & 41,9 & 369 & 116,9 & 31,7 \\
Egito & 228 & 3,8 & 1,7 & 340 & 176,8 & 52,0 \\
Chile & 124 & 31,7 & 25,6 & 269 & 71 & 26,4 \\
Canadá & 290 & 3 & 1,0 & 254 & 3 & 1,2 \\
\hline TOTAL* & 5.808 & 358,6 & 6,2 & 7.711 & $1.400,4$ & 18,2 \\
\hline
\end{tabular}

* 0 total de importação é a soma do volume importado pelos países do banco de dados do USDA Fonte: Dados trabalhados pelo autor com informações da ABIEC (2016) e da USDA (2017). 
O Canadá é outro país que figura entre os principais mercados importadores de carne bovina, mas que apresenta baixa participação dos frigoríficos brasileiros em seu mercado, em torno de 1\%, ao receber cerca de três mil toneladas de carne bovina do Brasil (Tabela 1). Já a União Europeia aplicava na importação de carne bovina desossada fresca ou refrigerada uma tarifa ad valorem em torno de $15 \%$, desde que a quantidade importada estivesse dentro do limite determinado pelo sistema de cota (Silva et al., 2008). Apesar dessa tarifa de importação, o bloco apresenta uma participação significativa do Brasil no volume importado, 41,9\% no ano 2000 e de $31,2 \%$ em 2016, ao serem enviadas 179.972 e 116.983 toneladas, respectivamente.

Em um contexto de protecionismo que restringe o acesso do setor frigorífico brasileiro aos países mais desenvolvidos, conforme explicam Lima e Hirst (2009, p. 50), adquiriu importância estratégica para o Brasil "[...] os ganhos econômicos e comerciais da cooperação com países em desenvolvimento”. Essa busca por novas cooperações comerciais é expressa no aumento do volume de remessas de carnes e da participação brasileira nos países considerados emergentes. Entre os anos de 2000 e 2016, por exemplo, as remessas de carne bovina do Brasil para a China subiram de 631 para 165.754 toneladas; o que repercutiu em um aumento da participação da produção brasileira naquele mercado de 3,9\% para $20,4 \%$, ou seja, um incremento de 16,5 pontos percentuais (Tabela 1 ).

Seguindo esse cenário, o mercado de Hong Kong que, no ano 2000, já apresentava participação significativa das remessas de carne do Brasil no volume importado, registrou um incremento de 30,4 pontos percentuais ao longo do período observado. Nos últimos anos, após negociações internacionais, o mercado egípcio também abriu suas portas ao produto brasileiro. Conforme a Tabela 1, em 2000, a exportação de 3.815 toneladas de carne bovina do Brasil representava somente 1,7\% do volume de 228 mil toneladas importadas pelo Egito; já em 2016, a participação brasileira subiu para $52 \%$.

Outra forma de protecionismo que incide sobre o setor frigorífico são as barreiras não tarifárias, sendo o sistema de cotas de importação de carne uma das formas mais utilizada de restringir a quantidade do produto estrangeiro a adentrar no país. A União Europeia é um importante mercado consumidor que adota o sistema de cotas para a importação de carnes do Brasil, tendo a "Cota GATT" e a "Cota Hilton". 
Para a importação de cortes de quartos dianteiros congelados, a União Europeia adota a “Cota GATT”. Essa cota determina a entrada total de 63.703 toneladas de carne bovina congelada no mercado europeu, volume que é disputado pelos países habilitados para exportar ao bloco, o que inclui Brasil, Argentina, Uruguai, Austrália etc. A tarifa aduaneira aplicada é de $20 \%$, mais um valor fixo por cada tonelada do produto que adentra o mercado europeu, variando de $€$ 994,5 até 2.138,4 euros (União Europeia, 2009).

Por sua vez, a Cota Hilton envolve os cortes selecionados (alcatra, contrafilé, filé mignon etc.) e com elevados preços. Com a Cota Hilton, a Comissão das Comunidades Europeias regulamentou os requisitos considerados necessários para a importação de carnes de bovino de alta qualidade e estabeleceu um direito aduaneiro ad valorem fixado em $20 \%$ sobre o valor de custo do produto (União Europeia, 2008).

Desde a criação da Cota Hilton em 1980, como discute Ameghino (2007), os países com maior participação no sistema de cota têm sido a Argentina e os Estados Unidos, juntamente com o Canadá, por serem considerados os países produtores de carne de melhor qualidade. Em 2005, a cota da Argentina era de 28.000 toneladas, valor superior à cota individual dos demais países participantes. Na sequência, configuravam com as cotas mais elevadas os Estados Unidos e Canadá (11.500 ton.), a Austrália (7.000 ton.), o Uruguai (6.300 ton.) e o Brasil, com uma cota de 5.000 toneladas (Ameghino, 2007).

Recentemente, a cota da Argentina passou a ser de $30 \mathrm{mil}$ toneladas, concentrando $44,6 \%$ da quantidade anual destinada aos países credenciados em 2015. Essa informação nos ajuda a compreender o interesse de frigoríficos brasileiros em adquirir unidades operacionais no território argentino. Em seguida, os EUA e o Canadá desfrutavam de uma cota conjunta de 11.500 toneladas (Beef Point, 2015). Já o Brasil, desde o ano de 2009, passou a deter uma cota de 10.000 toneladas, o dobro do que era determinado pelo sistema de cota até 2008. Esse incremento foi resultado de constantes negociações com o mercado europeu e comprovação da qualidade da carne bovina brasileira.

Os Estados Unidos, a Rússia e o Japão são outros exemplos de mercados que adotam o sistema de cotas para as importações de carnes. No caso dos Estados Unidos, segundo Abdenur (2005), estando isentos das cotas estadunidenses apenas o Canadá e o México, países que se 
beneficiavam de acesso livre sob o North American Free Trade Agreement (NAFTA [em português, Tratado Norte-Americano de Livre Comércio]). Para a carne bovina in natura, em 2005, o autor relata que a cota tarifária anual de exportações para os EUA era de 696.621 toneladas, incidindo uma tarifa de 4,4 centavos de dólar por quilo.

Os países que mais dispunham de volume de participação na cota estadunidense eram a Austrália (378.214 ton.), a Nova Zelândia (213.402 ton.), a Argentina e o Uruguai, esses últimos com cotas de 20 mil toneladas cada. Para os demais países interessados em exportar carne in natura para os EUA, inclusive o Brasil, restaria em torno de 65 mil toneladas de cotas a serem disputadas (Abdenur, 2005). Assim, conseguimos compreender o interesse de frigoríficos brasileiros em instalar unidades operacionais em países "beneficiados" pelo sistema de cota. A Argentina, o Uruguai e a Austrália, por exemplo, atraíram os interesses de grandes empresas brasileiras, as quais promoveram o IDE, com a abertura de unidades de produção em territórios estrangeiros.

Mazzali (2000) lembra que, desde a década de 1990, as cotas de importação aplicadas ao comércio internacional de carnes colocaram importantes desafios para o setor pecuário, destacando-se a necessidade de erradicação da febre aftosa do território brasileiro. De acordo com Neves et al. (2012), as empresas do setor frigorífico no Brasil estão atentas para as exigências do mercado internacional, com a implantação de medidas sanitárias que garantam uma melhor qualidade do produto.

As empresas que atuam no comércio exterior, conforme Nogueira (2006, p. 13), são as primeiras a perceber os problemas das barreiras comerciais; sendo que "as empresas brasileiras e seus representantes setoriais precisam tomar consciência de que é possível desafiar as barreiras comerciais dos outros países, e assim abrir novos mercados para seus produtos competitivos no mercado internacional". Pois o protecionismo de países desenvolvidos, como afirmam Bender Filho e Alvim (2008), dificulta as exportações de carne do Brasil, principalmente do produto in natura.

Para esses autores, somente a eliminação das barreiras não tarifárias e reduções nas tarifas provocariam um aumento considerável nas exportações. Distante de um mercado mundial sem barreiras, uma das medidas adotadas por empresas brasileiras para alavancarem as suas participações em mercados estrangeiros tem sido a abertura 
de plantas industriais no exterior, ou seja, avançam no processo de internacionalização e tornam-se multinacionais, com unidades de produção em locais estratégicos.

\section{A estratégia espacial da JBS S.A. para dominar o mercado mundial}

No setor frigorífico, a JBS (antiga Friboi) tornou-se a primeira empresa brasileira a realizar o IDE e adquirir unidades de produção no exterior. Em 2005, em uma negociação no valor de US\$ 200 milhões, a JBS comprou a Swift Armour S.A., empresa existente desde 1907 na Argentina e que se tornou a maior produtora e exportadora de carne bovina daquele país. Para a efetivação da compra, o BNDES concedeu ao grupo um financiamento de US\$ 80 milhões (Estadão, 2006). A aquisição incluía unidades operacionais, localizadas em Rosário e São José, as quais exportavam para 70 países, segundo Juliboni (2013), tendo os EUA como maior mercado importador.

Com a abertura de capital em 2007, a JBS negociou as suas ações na Bolsa de Valores de São Paulo. Naquele ano, as vendas das ações a um custo de $\mathrm{R} \$ 8,15$ cada gerou um montante de $\mathrm{R} \$ 1.853 .833 .020,00$, o que possibilitou a empresa expandir seu parque industrial, inclusive para fora do território nacional (JBS, 2008). Assim, o ano de 2007 marcou o momento de capitalização e de ampla dispersão geográfica do grupo.

No território argentino, em 2007, a empresa comprou os frigoríficos Berazategui e Colonia Caroya. Além de abastecer o mercado interno, a plataforma operacional na Argentina permitiu a JBS embarcar carne bovina para 43 países, com destaque para os Estados Unidos, União Europeia, Uruguai, Israel e Canadá (JBS, 2008). Já nos EUA, em julho de 2007, ocorreu a aquisição da Swift Foods \& Company, por US\$ 1,4 bilhão, uma das mais importantes empresas processadoras de carnes, existente desde 1855. Essa aquisição aumentou o portfólio da JBS, ao incluir os direitos sobre a marca em nível mundial. Assim, a empresa passou a comercializar carnes Swift em diversos países, incluindo consumidores na Europa, Ásia, América do Norte e América Latina (JBS, 2008).

A negociação contou com recursos financeiros do Banco Nacional de Desenvolvimento Econômico e Social, via mercado de ações, no valor de R\$ 1,1 bilhão (BNDES, 2014). Desta maneira, já em 2007, a BNDESPAR tornou-se uma importante acionista da JBS, detendo 12,95\% do seu capital 
social. Como discutem Fabrini e Gutierrez (2017), a compra de ações de empresas pelo banco estatal foi uma estratégia amplamente adotada nos governos de Luiz Inácio Lula da Silva e Dilma Rousseff, com o propósito de criar os "campeões nacionais" em alguns setores da economia.

Já em 2008, após a aquisição do Grupo Tasman, por cerca de 150 milhões de dólares, o parque industrial na Austrália passou a ser de dez plantas, com capacidade de abate de 8.500 cabeças de gado por dia e 16.500 cabeças de ovinos e suínos (Juliboni, 2013). Desta maneira, somente a plataforma de produção australiana conseguia comercializar carnes para 35 países, com destaque para a Coreia do Sul, China, Japão, Taiwan e Indonésia (JBS, 2008). No mesmo ano, a JBS continuou com a sua política expansionista nos Estados Unidos, adquirindo por US\$ 565 milhões os frigoríficos da Smithfield Beef Group e 12 fazendas de confinamento da Five Rivers (JBS, 2012).

Os investimentos diretos estrangeiros da JBS nos EUA e na Austrália, em 2008, contaram com o aporte do BNDES. O banco estatal investiu R \$ 335 milhões, via mercado de ações, e mais R \$ 662 milhões, por meio de um fundo de participações criado especialmente para a transação (BNDES, 2014). Já em 2009, o BNDES realizou um aporte de R \$ 3,5 bilhões para a JBS, por meio de debênture mandatoriamente conversível em ações, o que aumentou a participação da BNDESPAR no capital da multinacional brasileira, de 17\% para 23\%, entre 2008 e 2009 (BNDES, 2014).

No mesmo ano, a JBS investiu US\$ 800 milhões na aquisição de 64\% do capital social da Pilgrim's Pride Corporation, através de sua subsidiária JBS USA Holdings (JBS, 2009). O parque industrial da Pilgrim's Pride estava concentrado nos Estados Unidos, com 29 unidades de abate, tendo ainda três unidades de produção no México e outra localizada em Porto Rico; o que permitia a essa indústria processar entorno de 4,1 milhões de toneladas de frango por ano e exportar para mais de 80 países (JBS, 2009).

Nos países vizinhos do Brasil, em 2010, a JBS dispunha de duas plantas de abate de bovinos no Paraguai, situadas nas cidades de Assunção e de San António; e uma unidade operacional em Canelones (Uruguai), que pertencia ao Grupo Bertin e foi repassada para a JBS após o processo de fusão entre as duas empresas em 2009. Ressalta-se que o Grupo Bertin havia recebido um aporte de R $\$ 2,5$ bilhões da BNDESPAR, em 2008, pela aquisição de 27,5\% de seu capital social (BNDES, 2014). 
Em 2010, a JBS adquiriu as empresas australianas Tatiara Meat Company (TMC) e a Rockdale Beef. A partir da aquisição da Tatiara Meat, o grupo JBS ampliou a sua atuação no mercado de carne ovina na Austrália, nos Estados Unidos, Canadá e Europa, considerados consumidores mais exigentes. Já os ativos da Rockdale Beef incluíam fazendas de confinamento e frigoríficos de bovinos (JBS, 2011).

Em 2011, a JBS celebrou novos acordos comerciais para as suas plantas localizadas em países estrangeiros, por exemplo, as unidades dos Estados Unidos ampliaram suas exportações para mercados já consumidores (México, Canadá, Coreia do Sul etc.) e exportaram para mercados até então inexplorados pela empresa, como Japão e países do Sudeste Asiático. Enquanto a plataforma australiana tornou-se líder no mercado local e exportava cerca de $80 \%$ de sua produção, principalmente para países asiáticos e europeus (JBS, 2011). Isso demonstra que a localização de frigoríficos nesses países é parte da estratégia espacial da empresa para acessar importantes mercados.

Já em 2012, por meio de sua subsidiária nos Estados Unidos, a multinacional brasileira adquiriu os ativos da XL Foods, considerada a segunda maior empresa no setor de carne bovina da região. A aquisição envolvia quatro frigoríficos (dois nos Estados Unidos e dois no Canadá), uma propriedade rural e um confinamento no Canadá (JBS, 2012).

Em 2014, ao usar debêntures para subscrever novas ações, a participação do BNDES no capital social da empresa passou a ser de 24,6\%, com um total de 723.780.418 ações (JBS, 2014). Desde o início dos investimentos direto estrangeiros da JBS até 2014, o grupo obteve da BNDESPAR um aporte de $\mathrm{R} \$ 5,6$ bilhões, valor que representou 19,3\% do montante capitalizado pela empresa ( $\$ 29$ bilhões); já que no mercado financeiro a JBS havia levantado R $\$ 23,4$ bilhões (80,7\%), entre 2007 e 2014 (BNDES, 2014).

No ano seguinte, a JBS adquiriu os ativos do Grupo Primo Smallgoods, na Austrália e Nova Zelândia. Ainda em 2015, por US\$ 1,5 bilhão, a multinacional brasileira adquiriu os ativos da Moy Park Holdings Europe Limited. (JBS, 2016). Sendo uma das empresas líderes no processamento e vendas de carne de frango in natura e alimentos processados na Europa, com 13 unidades de processamento de aves localizadas na Inglaterra, Irlanda do Norte, França e Holanda. Já nos Estados Unidos, a JBS comprou a Cargill Pork, empresa dedicada ao 
processamento de carne suína e elaboração de produtos derivados que pertencia a Cargil Meat (JBS, 2017).

No Paraguai, em 2015, a JBS desembolsou US\$ 80 milhões na construção de um novo frigorífico, localizado em Belén (Departamento de Concepción), com o intuito de atender mercados externos (Rússia, Chile, Israel, Brasil etc.). Já em 2016, a JBS investiu na consolidação e integração de suas unidades nacionais e no exterior, uma vez que já possuía plataformas de processamento localizadas nos principais países produtores de proteína animal (Argentina, Austrália, Brasil, Estados Unidos, México, Uruguai etc.), com ampla rede de produção e distribuição que lhe permitia acessar os maiores mercados do mundo, comercializando para mais de 150 países (JBS, 2016).

Entre 2006 e 2016, a JBS apresentou um crescimento expressivo no número de unidades de produção (UP) no exterior que desempenhavam atividades no setor de proteína animal, passando de seis para 101 dessas filiais (Figura 1). Somente em 2009, a empresa somou mais 35 unidades de produção fora do Brasil, com a aquisição da Pilgrim’s Pride. Outra aquisição de destaque da JBS foi a Moy Park em 2015. Já em 2016, após a reabertura de unidades de abate e processamento que haviam sido paralisadas temporariamente, a multinacional brasileira contava com 101 unidades de produção ativas fora do território brasileiro, com atividades relacionadas à proteína animal.

Figura 1 - Unidades de produção da JBS no exterior e receita bruta, por mercado (2006-2016)

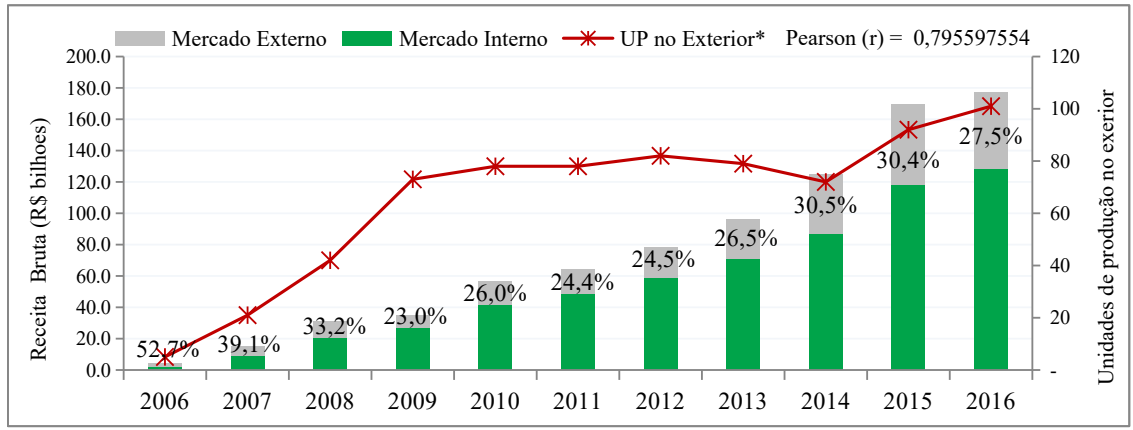

*. Unidades de Produção no exterior com atividades relacionadas à proteína animal (abate e/ou processamento).

Fonte: Dados trabalhados pelo autor com informações da JBS $(2008,2011,2012,2014,2016,2018)$. 
Ao longo do período observado na Figura 1, o número de UP no exterior favoreceu o aumento da receita operacional bruta da empresa, que passou de 4,75 bilhões, em 2006, para R\$ 176,89 bilhões, em 2016. Tal crescimento está relacionado a dois fatores: primeiramente, aos incrementos nas vendas no mercado interno, sendo que a empresa passou a contar com frigoríficos em diversos países, os quais abasteciam os mercados onde estavam instalados; segundo, os novos acordos de exportação que levaram ao aumento da receita com o mercado externo, uma vez que muitos países serviram de plataformas de exportação. Sendo válida a afirmação de Santos (2011, p. 151) sobre a dispersão geográfica de empresas multinacional, de que "[...] o objetivo final, em toda parte, é o aumento do lucro e a extração de uma taxa máxima de excedente".

No caso da JBS, o coeficiente de correlação linear de Pearson indica que as variáveis "UP no exterior" e "receita operacional bruta" estão positivamente associadas, pois o valor encontrado foi de 0,795 , o que significa uma correlação moderada/forte. Em relação à receita líquida, a diversificada estrutura operacional permitiu a empresa obter um montante de R \$ 170,38 bilhões em 2016; sendo que somente as operações da JBS no território norte-americano foram responsáveis por $68,9 \%$ desse valor (JBS, 2016).

Em relação à carne bovina, em 2016, a empresa detinha uma capacidade total de processar 84 mil cabeças por dia, em suas unidades de produção no Brasil, Paraguai, Uruguai, Argentina, Estados Unidos, Canadá e Austrália (Figura 2). No processamento de aves, a empresa dispunha de operações no Brasil, Estados Unidos, Reino Unido, México e Porto Rico, com uma capacidade total de abater 14,3 milhões de aves por dia; já na produção de carne suína, a empresa dispunha de plantas no Brasil, Austrália e Estados Unidos, com capacidade total de processar 111,2 mil suínos por dia (JBS, 2016).

Além do acesso direto aos mercados dos países em que realizou o IDE, a JBS passou a atender mercados antes restritos aos frigoríficos localizados no Brasil, sobretudo, na comercialização de carne in natura, como é o caso do Japão, Coreia do Sul, Taiwan, Estados Unidos, Canadá e México. Ou seja, a JBS obteve acesso a mercados que as concorrentes nacionais não podiam participar. Por isso, concordamos com Hilferding (1981) ao afirmar que o avanço no processo de internacionalização faz com que as medidas protecionistas sejam usadas pelas grandes empresas ao seu favor. 
Adentrando nas exportações, observa-se na Figura 2 que a plataforma localizada na Argentina, Paraguai e Uruguai possibilitou a JBS maior acesso ao mercado europeu, russo, estadunidense, chileno, israelense etc. Já a plataforma norte-americana da JBS (EUA e Canadá) possibilitou a empresa liderança no mercado regional e a exportação de carnes para diversos mercados (México, Coreia do Sul, Hong Kong, Indonésia, Japão, Taiwan, Chile, Colômbia etc.). A plataforma na Europa concedeu a JBS acesso direto ao mercado europeu (Inglaterra, Irlanda do Norte, França, Holanda, Espanha, Grécia, Alemanha etc.), e indireto em países do Oriente Médio e África (JBS, 2016).

Como esclarece Fischer (1979), a estratégia espacial amplia o controle da empresa sobre o mercado, pois o posicionamento apropriado garante proximidade aos fornecedores e acesso aos clientes. Por exemplo, a plataforma na Oceania (Austrália e Nova Zelândia) favoreceu as exportações para mercados locais, europeus e asiáticos, principalmente, China, Hong Kong, Japão, Coreia do Sul, Taiwan e Indonésia (Figura 2).

Figura 2 - Mapa das unidades de produção da JBS no exterior, com indicação dos principais mercados consumidores de carne bovina (2016)

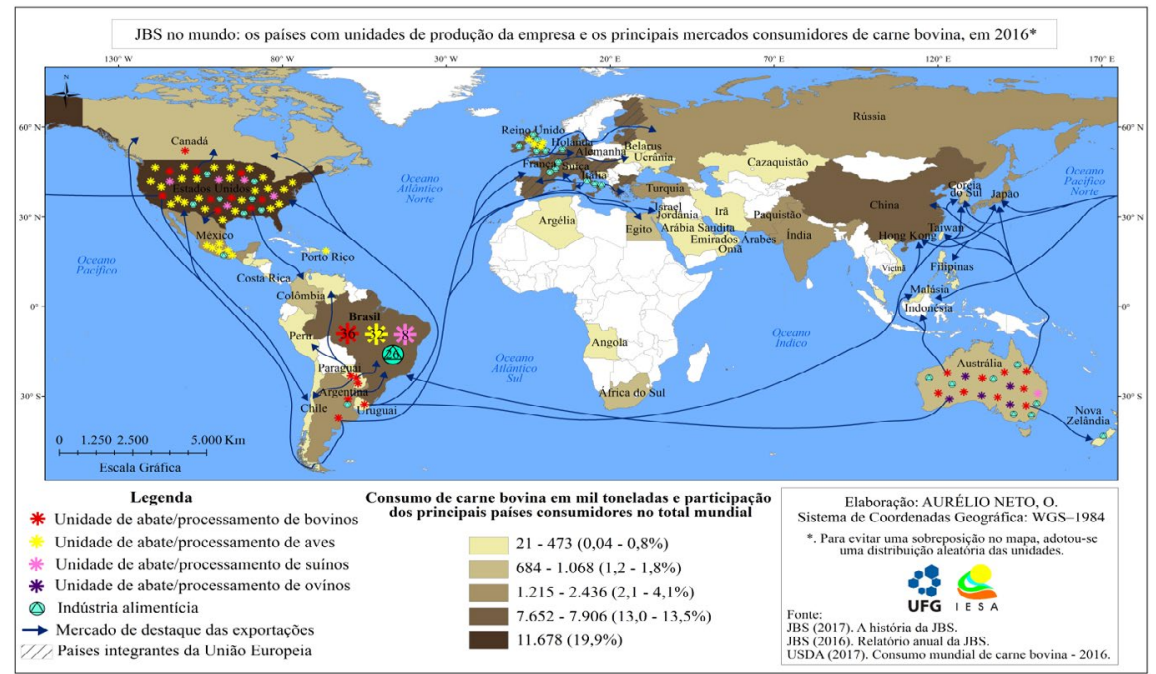

Fonte: JBS (2017 e 2016); USDA (2017). 
No processo de expansão geográfica e produtiva, entre 2005 e 2016, a JBS é considerada a empresa do setor frigorífico que mais obteve recursos financeiros do BNDES. Naquele intervalo temporal, o BNDES desembolsou $\mathrm{R} \$ 31,2$ bilhões para o setor de proteína animal, sendo que o aporte financeiro direcionado aos grupos JBS e Bertin representaram $26 \%$ e $12 \%$, respectivamente. Com a fusão desses dois grupos em 2009 , o montante que o banco estatal destinou a companhia representou $38 \%$ dos R \$ 31,2 bilhões. Sendo que R \$ 8,1 bilhões desse valor foram por meio de participação acionária da BNDESPAR. Assim, o banco estatal acabou "[...] dando acesso aos recursos necessários para a estratégia de aquisições da companhia” (BNDES, 2017, p. 244).

Contudo, o ano de 2017 ficou marcado pelos depoimentos dos irmãos Batista na Polícia Federal e suas delações à Procuradoria Geral da República, segundo Mendes et al. (2017), com informações de pagamentos de propinas para políticos e dirigentes de instituições públicas, entre as quais estava o BNDES. A operação deflagrada pela Polícia Federal constatou o uso irregular do dinheiro público e levou a um acordo de leniência, com aplicação de multa de R \$ 10,3 bilhões aos proprietários da JBS. Na sequência, o grupo JBS anunciou a venda de ativos no Mercosul e na Europa (Mendes et al., 2017).

Os ativos da JBS em países do Mercosul (Argentina, Paraguai e Uruguai) foram adquiridos pela empresa Minerva S.A. Ao contrário do que possa parecer, essa desterritorialização da JBS não significa o fim da maior multinacional da carne. Conforme explica Andrade (1998), a desterritorialização pode levar a reorganização da empresa em outros espaços que apresentem melhores condições de gestão e uso; comportamento que tem sido demonstrado pelo grupo empresarial, sobretudo nos Estados Unidos.

\section{A estratégia espacial da Minerva Foods S.A. na América do Sul}

A primeira aquisição de uma unidade de produção no exterior pela Minerva ocorreu no Paraguai, em 2008. Para tanto, a empresa desembolsou US\$ 5 milhões na compra de 70\% do capital social da Friasa S.A., frigorífico localizado em Assunção (Minerva, 2011). O Paraguai já figurava entre os maiores exportadores de carne bovina; além disso, o país havia sido reconhecido internacionalmente como área livre de aftosa. Assim, 
a aquisição deu acesso direto ao mercado paraguaio, além de permitir a celebração de novos acordos com mercados estrangeiros (Minerva, 2012).

Com a venda de ações no mercado de capitais em 2007, a Minerva captou R\$ 444 milhões, recurso financeiro que contribui para o seu processo de expansão geográfica e produtiva (BNDES, 2014). Apesar de mais comedido, a expansão da Minerva contou também com o fomento do governo, por meio de uma diversificada carteira de financiamentos envolvendo o Banco da Amazônia (Basa) em 2007, com uma linha de crédito de R\$ 55,215 milhões; o BNDES em 2009, com uma linha de fomento de R \$121,9 milhões; e a Financiadora de Estudos e Projetos (FINEP) em 2010, com um aporte de R \$ 57,208 milhões (Minerva, 2012).

Além dessas linhas de crédito, a empresa realizou a emissão de títulos de dívida no exterior em 2010, com o intuito de se capitalizar e avançar em sua internacionalização (MINERVA, 2011). Já em 2011, a Minerva realizou um IDE para a aquisição do Frigorífico Pul, localizado na cidade de Melo (Uruguai). Essa unidade produtiva atuava no abate de bovinos e desossa, sendo $85 \%$ de suas vendas destinadas ao mercado externo, uma vez que desfrutava de habilitação para exportar carne in natura aos rigorosos mercados dos Estados Unidos e União Europa (Minerva, 2011).

A empresa Minerva percebia a existência de mão de obra, recursos naturais abundantes, clima favorável à criação de gado e a disponibilidade de terras por baixo preço de aquisição, como vantagens competitivas da produção localizada na América do Sul (Minerva, 2012). Isso se tornar mais emblemático ao considerar os altos custos de produção de outros países, como os Estados Unidos e a Austrália. Assim, a dispersão geográfica fora do Brasil continuou em 2012, na América do Sul, ao adquiri o Frigomerc S.A., unidade de produção localizada em Assunção, Paraguai (Minerva, 2012).

Em 2012, essa multinacional brasileira realizou uma nova oferta pública de ações na bolsa de valores, o que contribuiu ampliar o seu parque industrial. No ano seguinte, a International Finance Corporation (IFC) tornou-se acionista da Minerva, ao realizar um aporte financeiro de $\mathrm{R} \$ 46,9$ milhões e adquirir 2,9\% do capital social da companhia (Minerva, 2013). A IFC é uma espécie de departamento do Banco Mundial que realiza investimentos no setor privado, passando a ser um importante aliado da Minerva em seu plano de investimento, ao auxiliar no acesso aos recursos 
financeiros. Como consta no relatório de 2013, a Minerva firmou com a IFC um contrato de empréstimo, no valor de R\$ 137,7 milhões, a ser pago em um prazo de dez anos.

Em 2014, a Minerva retoma a sua dispersão geográfica no exterior, com a aquisição do Frigorífico Carrasco, no Uruguai. Já em 2015, a companhia adquiriu 100\% das ações da empresa Red Industrial Colombiana, passando a controlar o Frigorífico Red Cárnica, localizado no Departamento de Córdoba, considerada a maior região produtora e exportadora de carne bovina daquele país. O frigorífico exportava para o Oriente Médio, Rússia, Egito, Hong Kong, Venezuela, Peru e Angola (Minerva, 2015).

Ainda em 2015, por meio de sua subsidiária no Paraguai (Frigomerc S.A.) a Minerva celebrou um contrato de locação com a DIGNA S.A. para alugar o Frigorífico Expacar, localizado na cidade de Assunção (Minerva, 2015). Naquele ano, a multinacional investiu $R \$ 220,2$ milhões em seu parque industrial, dos quais $\mathrm{R} \$ 156,8$ milhões foram alocados para a manutenção dos ativos e R \$ 63,4 milhões foram destinados à expansão de suas operações, no Brasil e no exterior (Minerva, 2016).

Em relação aos investimentos, Ondei e Moitinho (2017) relatam o ingresso da Saudi Agricultural and Livestock Investment Company (SALIC) no capital social da Minerva, após um aporte de R\$ 746,4 milhões por $20 \%$ de participação na companhia. Assim, a empresa passou a contar com recursos do Fundo Soberano da Arábia Saudita e estabeleceu uma parceria importante para atuar no Oriente Médio e outros países da Ásia.

Em 2016, a empresa contava com companhias de exportação (tradings) localizadas no Uruguai e Austrália, desenvolvendo canais mais eficientes para o envio de seus produtos aos mercados estrangeiros. No caso da trading australiana, o IDE da Minerva visava expandir a participação da empresa no mercado asiático, uma região com crescimento populacional expressivo e alto potencial na demanda por proteína animal.

No final do ano de 2016, a Minerva já contava com 17 unidades operacionais e uma capacidade de abate diária de 17.330 cabeças e de desossa de 3.153 toneladas, sendo 11 frigoríficos localizados no Brasil, três no Paraguai, duas plantas no Uruguai e outra na Colômbia; além das unidades de abate e processamento, a empresa operava 11 centros de distribuição, dos quais oito estavam no Brasil e os demais localizados em Assunção (Paraguai), Bogotá (Colômbia) e Santiago, capital do Chile (Minerva, 2016). 
Entre as multinacionais brasileiras da carne (JBS, Minerva, Marfrig e BRF), a Minerva foi a que teve o crescimento mais comedido no número de unidades de produção no exterior, passando de uma UP, em 2008, para seis plantas, em 2016 (Figura 3). Os frigoríficos fora do Brasil favorecem o incremento da receita operacional bruta da empresa, que subiu de 2,3 bilhões para mais de $\mathrm{R} \$ 10,2$ bilhões, no mesmo intervalo temporal. No caso da Minerva, o coeficiente de correlação de Pearson indica uma forte associação linear $(0,985)$, entre as variáveis "UP no exterior" e "receita operacional bruta".

Figura 3 - Unidades de produção da Minerva no exterior e receita bruta, por mercado (2008-2016)

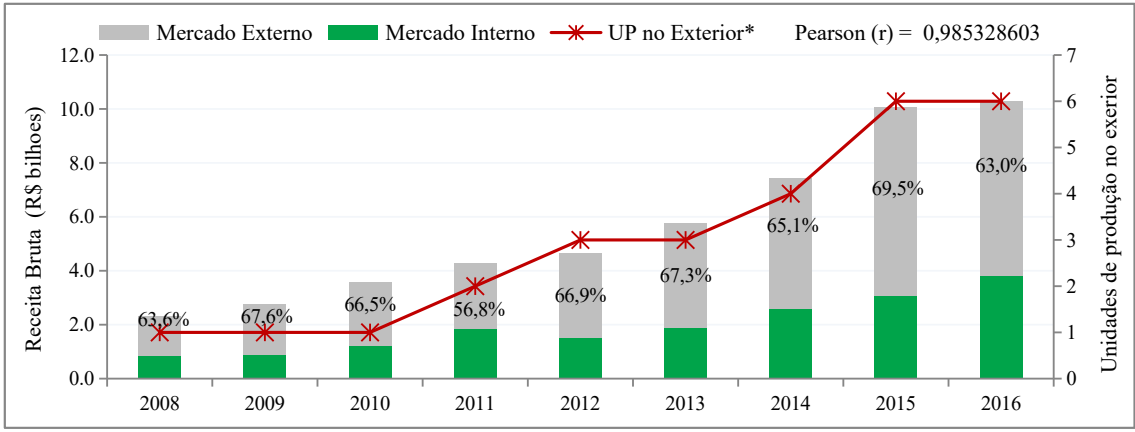

*. Unidades de Produção no exterior com atividades relacionadas à proteína animal (abate e/ou processamento).

Fonte: Dados trabalhados pelo autor com informações da MINERVA (2011, 2012, 2013, 2015, 2016).

Ao longo do período analisado, observa-se no gráfico que mais de $50 \%$ da receita da Minerva era proveniente das exportações, o que demonstra o interesse da empresa em mercados estrangeiros. Nos anos de 2015 e 2016, as seis unidades de produção no exterior serviam como plataformas de exportação, de maneira que contribuíram para as vendas no mercado externo superarem os R 6 bilhões, juntamente com os frigoríficos exportadores localizados no Brasil. Naquele biênio, o mercado externo representou $69,5 \%$ e $63 \%$ da receita operacional, respectivamente (Figura 3).

Já em 2017, com a aquisição de unidades da JBS, o quadro de unidades operacionais da Minerva subiu para 27 plantas, contando com 15 frigoríficos no exterior e uma unidade de alimentos industrializados na Argentina. De modo que a plataforma de abate de gado da Minerva em países vizinhos ao 
Brasil era constituída por seis frigoríficos no Paraguai, cinco na Argentina, três no Uruguai e um frigorífico na Colômbia (Figura 4).

Figura 4 - Mapa das unidades de produção da Minerva no exterior, com indicação dos principais mercados consumidores de carne bovina (2017)

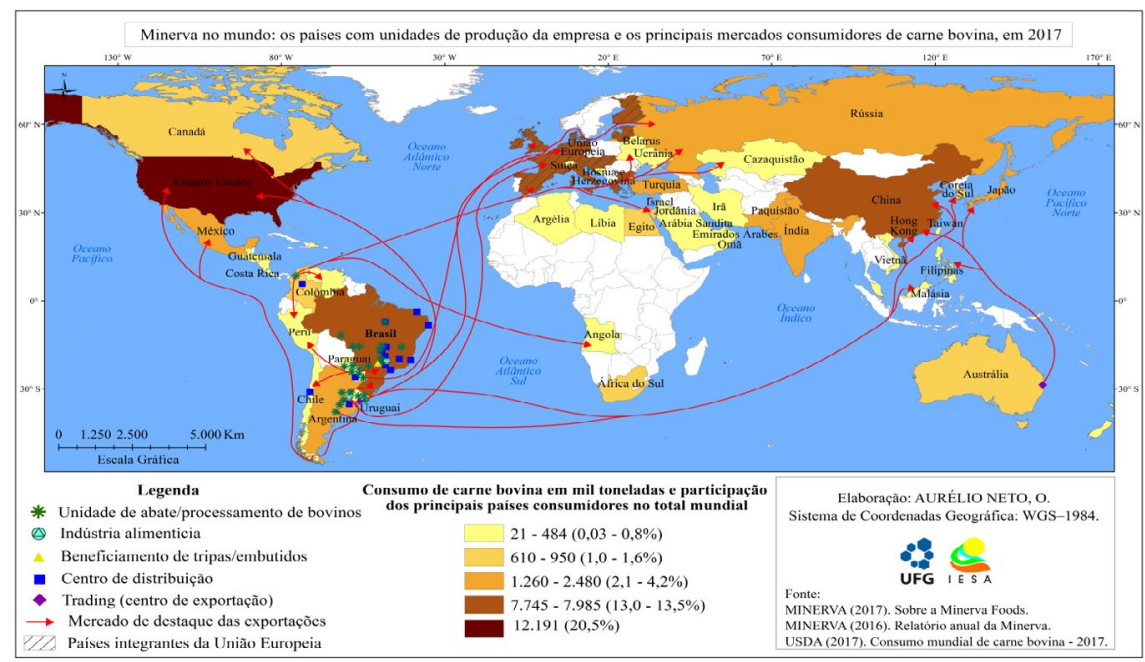

Fonte: Minerva (2017, 2016); USDA (2017).

Com a estratégia espacial de internacionalização a empresa ampliou a sua carteira de clientes e exportava para mais de 100 países, com atuação na Ásia, Oriente Médio, África, União Europeia, países do leste europeu, América do Norte e América Latina. A partir do frigorífico localizado na Colômbia, a empresa exportava para a Rússia, Peru, Curaçao, Venezuela, Hong Kong, Espanha, Egito, Angola, Líbia, Cazaquistão, Líbano e Jordânia, entre outros mercados (Minerva, 2015).

As unidades operacionais na Argentina permitiram a empresa aumentar a sua participação no mercado mundial de carne, com exportações para a União Europeia, Rússia, Estados Unidos, México, Brasil e China, entre outros. Das unidades operacionais no Paraguai, país em que a Minerva desenvolveu uma linha premium de cortes de carnes em 2016, os principais mercados de destino foram: Chile, Rússia, Brasil, Peru, Venezuela e países do Oriente Médio, sobretudo, Israel, Líbano e Emirados Árabes Unidos. Por sua vez, entre os mercados atendidos pelos frigoríficos 
no Uruguai, destaca-se a China, Estados Unidos, Holanda, Canadá, México, Itália, Reino Unido, Alemanha, Suíça, Coreia do Sul, Cingapura, Malásia, Filipinas e Taiwan (Minerva, 2015, 2016).

No final de 2017, em trabalho de campo no frigorífico localizado em Canelones (Uruguai), pôde-se verificar que a unidade já funcionava normalmente sob o comando da Minerva (Figura 5). Com capacidade de abate de 900 bovinos por dia, a unidade de produção em território uruguaio manteve os cerca de 600 antigos funcionários da JBS para continuar as operações, conforme informou o supervisor da unidade. $\mathrm{O}$ frigorífico em Canelones desfrutava de habilitações de exportação para mais de 50 mercados, entre os quais estavam a União Europeia, Estados Unidos, Rússia e China.

Percebe-se na Figura 5 que a logomarca da JBS já havia sido retirada da fachada do frigorífico, mas a empresa compradora não se importou em colocar a sua. O principal interesse da Minerva estava nas marcas e nos acordos comerciais advindos com as aquisições de unidades de produção no exterior, uma vez que os frigoríficos localizados na Argentina, Paraguai e Uruguai, exportavam para alguns dos principais mercados consumidores de carne bovina no mundo.

Figura 5 - Frigorífico Canelones, no Uruguai, vendido pela JBS para a Minerva (2017)

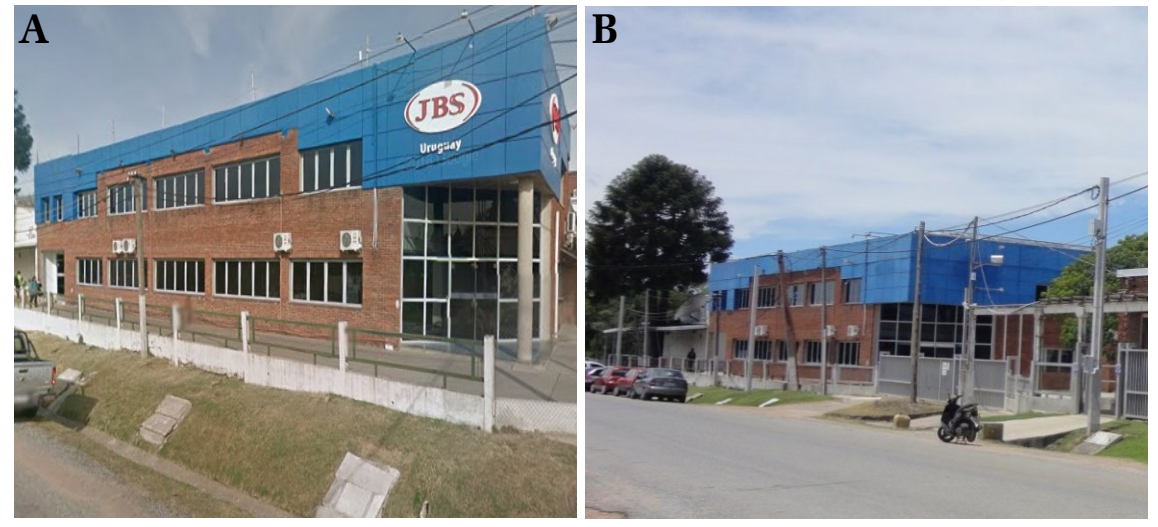

Legenda: (A) Frigorífico no município de Canelones, interior do Uruguai, ainda sob o controle da JBS, observa-se a logomarca da empresa em agosto de 2015. Fonte: G00GLE MAPS (2015). (B) 0 mesmo frigoríico, mas sob o comando da Minerva, sem a logomarca daquela empresa concorrente.

Fonte: Do autor (2017). 
Portanto, as aquisições de unidades da JBS em países vizinhos ao Brasil foram estratégicas para a Minerva. Isso corrobora com a afirmação de Santos (2015, p. 33) de que "as empresas na busca da mais-valia desejada, valorizam diferentemente as localidades". Concordamos com esse geógrafo que os locais são escolhidos com base em suas condições físicas, infraestrutura, abertura comercial e outras vantagens que permitam a empresa maior inserção e aproveitamento do território estrangeiro. Entre essas vantagens temos a mitigação dos efeitos de barreiras comerciais, como se verificou nos casos das multinacionais JBS e Minerva.

\section{Considerações finais}

O setor frigorífico é um dos complexos agroindustriais em que incidem barreiras comerciais, o que tende a reduzir a participação de empresas brasileiras no mercado mundial. Para contornarem impasses no comércio internacional e ampliarem suas áreas de atuação, a JBS e a Minerva investiram na estratégia espacial de internacionalização, com a dispersão geográfica de unidades de produção no exterior. As empresas escolheram estrategicamente os locais e realizarem o IDE.

As políticas públicas voltadas à promoção do IDE de empresas nacionais contribuíram para o surgimento das multinacionais brasileiras da carne, destacando-se o papel do BNDES/BNDESPAR nos aportes financeiros. Entretanto, os recursos de cofres públicos não se constituíram nas únicas fontes de capitalização das empresas pesquisadas. A abertura de capital social, com a venda de ações, demonstrou-se essencial para a captação de recursos e a realização de investimentos fora do território brasileiro. Sendo que a Minerva, ao contar com um menor volume de recursos do banco estatal que a sua concorrente, buscou financiamentos e parcerias com o capital estrangeiro.

Ressalta-se que alguns mercados situados na América do Norte, Ásia e Oriente Médio, que impunham restrições ao setor frigorífico brasileiro, tornaram-se mais acessíveis para as empresas pesquisadas devido à localização de unidades de produção no exterior. Assim, as multinacionais brasileiras driblaram os efeitos de algumas medidas protecionistas e conseguiram uma maior participação em mercados estrangeiros, seja com o acesso direto das filiais aos consumidores nas quais se instalaram ou com os novos acordos comerciais de exportação. Desta maneira, em escala global, a JBS e a Minerva ampliaram suas receitas operacionais. 
Nota

1 Este artigo é baseado em um dos capítulos de minha tese de doutorado defendida no Programa de Pós-Graduação em Geografia, do Instituto de Estudos Socioambientais IESA-UFG, em março de 2018. Agradeço à Coordenação de Aperfeiçoamento de Pessoal de Nível Superior (CAPES) pela concessão da bolsa de pesquisa durante o período de realização do doutorado.

\section{Referências}

ABDENUR, R. Barreiras a produtos e restrições a serviços e investimentos nos EUA. 4. ed. Embaixada do Brasil em Washington /Ministério das Relações Exteriores (Org.). São Paulo: Ed. Aduaneiras; LEX Editora, 2005. 156 p.

ABIEC. Relatório das Exportações Brasileiras de Carne Bovina: 2000-2016. 2016. Disponível em: <http://www.abiec.com.br/Exportacoes.aspx>. Acesso: $30 \mathrm{mar}$. 2017.

AMEGHINO, E. A. La carne vacuna argentina: historia, actualidad y problemas de una agroindustria tradicional. Buenos Aires: Imago Mundi, 2007. 320 p.

ANDRADE, M. C. de. Territorialidades, desterritorialidades, novas territorialidades: os limites do poder nacional e do poder local. In: SANTOS, M.; SOUZA, M. A. A.; SILVEIRA, M. L. (Org.). Território, globalização e fragmentação. 4. ed. São Paulo: HUCITEC - ANPUR, 1998. p. 213-220.

BEEF POINT. UE registra maior utilização global da cota Hilton em 2014-15. 2015. Disponível em: <http://www.beefpoint.com.br/ue-registra-maior-utilizacaoglobal-da-cota-hilton-em-2014-15/>. Acesso em: 03 nov. 2017.

BENDER FILHO, R.; ALVIM, A. M. O mercado de carne bovina no Brasil: os efeitos da eliminação das barreiras tarifárias e não tarifárias. Revista de Economia e Sociologia Rural, v. 46, n. 4, p. 1095-1127, 2008.

BNDES. Livro verde: nossa história tal como ela é. Rio de Janeiro: BNDES, 2017. $333 \mathrm{p}$.

. O crescimento de grandes empresas nacionais e a contribuição do BNDES via renda variável: os casos da JBS, TOTVS e Tupy. Rio de Janeiro: BNDES; Centro de Gestão de Estudos Estratégicos (CGEE), 2014. 120 p.

BRANDT, W. K.; HULBERT, J. M. A empresa multinacional no Brasil. Rio de Janeiro: Zahar, 1977. 183 p.

DA MATA, D.; FREITAS, R. E. Exportações agropecuárias e características dos países importadores. In: DE NEGRI, J. A.; ARAÚJO, B. C. P. O. (Org.). As empresas brasileiras e o comércio internacional. Rio de Janeiro: IPEA, 2006. p. 371-396.

ESTADÃO. Friboi compra frigorífico na Argentina. 2006. Disponível em: <http:// economia.estadao.com.br/noticias/mercados,friboi-compra-frigorifico-naargentina,20061130p17963 >. Acesso: 2 nov. 2016. 
FABRINI, F.; GUTIERREZ, M. Relatório do TCU indica favorecimento do BNDES à JBS. 2017. Disponível em: <http://economia.estadao.com.br/noticias/ geral,relatorio-do-tcu-indica-favorecimento-do-bndes-a-jbs, 70001752102>. Acesso em: 29 dez. 2017.

FISCHER, A. Politique régionale et stratégie spatiale de la grande firme. L’exemple de Philips aux Pays-Bas. Norois Année, v. 101, n.1, p. 49-66, JanvierMars, 1979.

GOOGLE MAPS. Frigorífico Canelones. Google, Inc., Califórnia (EUA), Street View, ago. 2015. Disponível em: < https://www.google.com.br/maps/>. Acesso: 20 nov. 2017.

HILFERDING, R. Finance Capital: a Study of the Latest Phase of Capitalist Development. London: Routledge \& Kegan Paul; Ed. Tom Bottomore, 1981. 466 p.

LIMA, M. R. S.; HIRST, M. Brasil como país mediador e poder regional. In: HURRELL, A. et al. (Org.). Os BRICS e a ordem global. Rio de Janeiro: FGV, 2009. p. 43-73.

JBS. A história da JBS. 2017. Disponível em: < http://jbs.com.br/sobre/historia/>. Acesso em: 20 jul. 17.

. Relatório Anual da JBS: 2016. 2016. Disponível em: < http://jbss. infoinvest.com.br/ptb/4069/JBS\%20RAS\%202016\%20PT\%20170502\%20Final. pdf>. Acesso em: 12 nov. 2017.

- Relatório Anual da JBS: 2014. 2014. Disponível em: < http://jbss. infoinvest.com.br/ptb/4361/20150601_RelatorioJBS_portugues menor.pdf $>$. Acesso em: 15 fev. 2016.

. Relatório Anual da JBS: 2012. 2012. Disponível em: < http://jbss. infoinvest.com.br/ptb/2496/JBS_RA12 completo1.pdf > . Acesso em: 15 fev. 2016.

. Relatório Anual da JBS: 2011. 2011. Disponível em: < http://jbss.infoinvest. com.br/ptb/2200/JBS Relatorio_Anual_2011.pdf>. Acesso em: 15/02/2016.

- Relatório Anual da JBS: 2009. 2009. Disponível em: < http:// relatorioanual2009.jbs.com.br/relatoriojbs.riweb.com.br/home.html >. Acesso em: 08/11/2017.

. Relatório Anual da JBS: 2008. 2008. Disponível em: < http://jbss.infoinvest. com.br/ptb/2202/JBS_RA2007_Consolidado.pdf>. Acesso em: 15 fev. 2016.

. Relatórios CVM: Informações Financeiras (2007-2017). 2018. Disponível

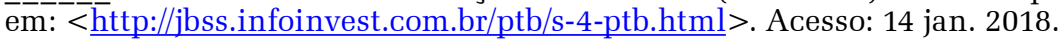

JULIBONI, M. As principais aquisições do JBS nos últimos anos. Exame, São Paulo, 10 jun. 2013. Disponível em: <https://exame.abril.com.br/negocios/asprincipais-aquisicoes-do-jbs-nos-ultimos-anos/>. Acesso em: 21 set. 2016.

MATHEWS, J. A. Dragon multinationals: new players in 21st century globalization. Asia-Pacif Jornaul of Management, v. 23, n. 1, p. 5-27, 2006.

MAZZALI, L. O processo recente de reorganização agroindustrial: do complexo à organização "em rede”. São Paulo: UNESP, 2000. 175 p. 
MENDES, L. H.; ADACHI, V.; TORRES, F.; GÓES, F. A saga da JBS. Valor Econômico, São Paulo, 07 jul. 2017. Disponível em: < http://www.valor.com.br/ especial/jbs >. Acesso em: 28 nov. 2017.

MICHALET, C-A. O que é a mundialização? São Paulo: Loyola, 2003. 238p.

MINERVA. Relatório de Sustentabilidade da Minerva 2016. 2016. Disponível em: $<$ http://online.flipbuilder.com/bkyt/nged/mobile/index.html >. Acesso em: 18 dez. 2017.

Relatório de Sustentabilidade da Minerva 2015. 2015. Disponível em: <http://portal.minervafoods.com/files/02896-006_relatorio 2015 internet. pdf>. Acesso em: 18 dez. 2017.

. Relatório de Sustentabilidade da Minerva 2013. 2013. Disponível em: < http://sustentabilidade.minervafoods.com/ >. Acesso em: 15 mar. 2016.

. Relatório de Sustentabilidade da Minerva 2012. 2012. Disponível em: <http://www.mzweb.com.br/minerva2012/web/download arquivos.asp?id arquivo=F81344ED-9594-4F63-8B12-504305A37E21 >. Acesso em: 15 mar. 2016.

. Relatório de Sustentabilidade da Minerva 2011. 2011. Disponível em: < http:/ portal.minervafoods.com/files/beef3_rs_2011_port.pdf > . Acesso: 15 mar.2016.

- Sobre a Minerva Foods: história. Disponível em: < http://portal. minervafoods.com/sobre-minerva-foods\#historia >. Acesso: $17 \mathrm{dez} .2017$.

NEVES, M. F. et al. Estratégias para a carne bovina no Brasil. São Paulo: Atlas, 2012. 272 p.

NOGUEIRA, S. P. L. Como derrubar as barreiras internacionais de comércio. São Paulo: Lex Editora, 2006. 122 p.

ONDEI, V.; MOITINHO, F. O apetite do Minerva. Dinheiro Rural, 03 ago. 2017. Disponível em: < https://www.dinheirorural.com.br/o+apetite+do+minerva $>$. Acesso em: 05 jan. 2018.

ORDONEZ, H. et al. Caso PRINEX: inovação e competitividade em gados e carnes. In: VILELLA, F.; NEVES, M. F.; SENESI, S.; PALAU, H. (Ed.). Agronegócios em Argentina e Brasil: uma estratégia conjunta e uma visão ao futuro. Buenos Aires: Ed. Faculdade de Agronomia, UBA, 2007. p. 1-82.

ROGERSON, P. A. Métodos estatísticos para geografia: um guia para o estudante. 3. ed. Porto Alegre: Bookman, 2012. 348 p.

SANTOS, M. Por uma outra globalização: do pensamento único à consciência universal. 24. ed. Rio de Janeiro: Record, 2015. 174 p.

$\overline{2} \overline{0} \overline{1} . \overline{2} 08 \mathrm{p}$.

. Economia espacial: críticas e alternativas. 2. ed. São Paulo: EDUSP,

SILVA, S. Z. da; TRICHES, D.; MALAFAIA, G. Reflexões sobre as barreiras não tarifárias às exportações na cadeia de carne bovina brasileira. IPES - Instituto de Pesquisas Econômicas e Sociais, Caxias do Sul, n. 32, maio 2008.

UNIÃO EUROPEIA. Regulamento (CE) n. 810, de 11 de agosto de 2008. Cota Hilton - União Europeia. Disponível em: <http://eur-lex.europa.eu/legal-content/ PT/TXT/PDF/?uri=CELEX:32008R0810\&from=EN>. Acesso: 07 out. 2017. 
. Regulamento (CE) $n^{\circ}$ 880, de 7 de setembro de 2009. Regulamentos da pauta aduaneira - União Europeia. Disponível em: <http://eur-lex.europa.eu/ legal-content/PT/TXT/PDF/?uri=CELEX:32009R0880\&from=EN>. Acesso: 07 out. 2017.

USDA. United States Department of Agriculture. Foreign Agricultural Service: Database (2000-2017). Disponível em: < https://www.fas.usda.gov/>. Acesso em: 21 jan. 2018.

Onofre Aurélio Neto - Graduado em Geografia pela Universidade Federal de Goiás. Mestre e Doutor em Geografia pela mesma Universidade. Atualmente é docente na Secretaria Municipal de Educação e Esporte, em Goiânia-G0. (iD https://orcid.org/0000-0002-2311-839X

Recebido para publicação em 10 de dezembro de 2018 Aceito para publicação em 25 de janeiro de 2019 Publicado em 23 de fevereiro de 2019 